\title{
Voces que tienen usos condicionados. Su incorporación en diccionarios de aprendizaje*
}

\author{
ENCARNA ATIENZA CEREZO \\ Universitat Pompeu Fabra
}

\section{INTRODUCCIÓN}

Actualmente se están llevando a cabo varios proyectos sobre diccionarios de marcadores discursivos, cuya caracterización lexicográfica comporta necesariamente un acercamiento pragmático de tales voces ( $c f$. Santos 2003, así como los proyectos actualmente en marcha de Briz, por un lado, y Martín Zorraquino, por otro). Sin embargo, voces propiamente sustantivas, adjetivas o verbales parecen resistirse a un tratamiento lexicográfico que incorpore explicación pragmática, entendiendo como tal la inclusión de marcas diastráticas, marcas de énfasis, actos de habla codificados, situación comunicativa en que se utilizan las voces (antecedentes y requisitos de la situación así como número, condición y actitud de los participantes); canal oral o escrito, diferentes registros, etc. La introducción de explicación pragmática en los diccionarios implica, por lo tanto, información acerca del uso que se hace de ciertas voces más allá de su significado y de sus restricciones léxico-semánticas y sintácticas (Sinclair 1987, Leech y Thomas 1987, Yang 2007, entre otros).

En los últimos años, la noción de explicación pragmática en lexicografía, de la mano de Leech y Thomas (1987) y de Sinclair (1987), se ha convertido en centro de atención por parte de los lexicógrafos. Es obvio, como señala Nuccorini (1993: 216), que el papel de los factores pragmáticos como claves para la comunicación no ha sido desestimado por los diccionarios de aprendizaje, tampoco en la lexicografía española. Como recoge Yang (2007: 147) y ya había descrito Thomas (1983: 100), no hace falta insistir en que no todos los errores de lengua que produce un aprendiente tienen que ver con la gramática y el significado codificado de las palabras, sino que una considerable proporción de errores se deben a un desconocimiento pragmático. Por tanto, debido a la importancia que cobra la competencia pragmática en la interacción, un diccionario de aprendizaje debería incorporar, más allá de las marcas y notas de uso, explicación pragmática con el fin de resultar una herramienta útil para el destinatario del mismo, aun a sabiendas de que resulta más difícil y complejo codificar en la definición el comportamiento pragmático de las voces.

En cualquier caso, la tendencia lexicográfica actual se dirige — casi intuitivamente- a la incorporación de los usos pragmáticos de las palabras, de modo que el usuario no yerre en su empleo, como preconiza la llamada pragmática léxica ( $c f$. Jiménez 2001). Esto supone, formalmente, dar un giro en la estructuración del artículo lexicográfico, pues en el momento de

*Este trabajo se inscribe en el proyecto HUM2006-06982, Las categorías de verbo y adverbio en el DAELE, Dirección General de Enseñanza Superior e Investigación Científica (2006-2009), cuya Investigadora Principal es M. Paz Battaner Arias (UPF). 
querer la lexicografía hacer del diccionario una herramienta —no solo de decodificación sino también de codificación - sobre el uso de las palabras, se topa, por un lado, ante la imposibilidad de definiciones parafrásticas totalmente sustitutorias de la voz definida, y, por otro, ante la necesidad de incorporar una explicación sobre el uso, más allá de codificar información gramatical o sinónimos del lema.

Como se destaca en el prólogo del Diccionario del español actual (1999) (en adelante $D E A)$, la explicación de las palabras desde un punto de vista pragmático resulta insuficiente si no se dice cómo funcionan en la frase, en qué medida su presencia y sentido condiciona la estructura del contexto, cuáles son sus condiciones con otros elementos del contexto (DEA: XI). En algunos diccionarios, como en el Diccionario de uso del español (2001) (en adelante DUE) o en el $D E A$, esto se ha salvado con definiciones propias e impropias. El $D E A$ es el más tajante al poner en cursiva la información dada sobre una voz o una acepción que no constituye la definición.

\section{PlanteAmiento de LA INVESTigacióN}

Nuestro objeto de análisis va a ser el tratamiento pragmático dado en el $D U E$, por un lado, y en tres diccionarios de aprendizaje, por otro, a voces sustantivas, adjetivas y verbales que caen fuera de la fraseología propiamente dicha, y están condicionadas a alguna situación enunciativa que resulte relevante para el usuario. Los diccionarios de aprendizaje analizados son: el Diccionario Salamanca (1996) (en adelante Salamanca), el Diccionario para la enseñanza de la lengua española (2000) (en adelante DIPELE) y el Diccionario de español para extranjeros (2002) (en adelante $D E E$ ). Para ello, seguiremos los siguientes pasos:

1. Búsqueda de explicación pragmática en las definiciones del $D U E$, a partir de la búsqueda de expresiones verbales que, a priori, por su estructura sintáctica y valor semántico, parecen hacer posible la introducción de dicha explicación.

Partimos de una primera búsqueda en el DUE de la presencia de este tipo de información en los diccionarios monolingües de lengua española. La consulta electrónica de este diccionario permite encontrar coincidencias, constantes que en una consulta manual pueden pasar desapercibidas. Tales constantes, creadas desde la intuición lexicográfica de María Moliner sobre el uso de las palabras, pueden permitir llegar a una sistematización que ayude a trabajos lexicográficos posteriores sobre diccionarios de aprendizaje a la codificación pragmática. En una consulta rápida de este diccionario, puede constatarse que, además de las marcas de uso, se vale de una serie de expresiones verbales explicativas con las que se da cabida a definiciones impropias, para dar razón de esta explicación necesaria, pero no propiamente semántica: se usa, indica, destaca, etc.

2. A partir del análisis de las expresiones verbales empleadas en el $D U E$, se lleva a cabo una propuesta de un patrón para la incorporación de la explicación pragmática. El fin último es poder sistematizar un patrón que permita la incorporación, de un modo regular y sistemático, de la explicación pragmática condicionada por el uso de las voces. La configuración de tal patrón pretende servir en la ulterior elaboración de diccionarios de aprendizaje de nueva planta, como un modo de «incluir en la obra lexicográfica el uso comunicativo del léxico, de modo que permita al usuario del diccionario averiguar la carga de cognición sociocultural que este lexema conlleva» (Jiménez 2001: 40).

3. Una vez esbozado un patrón para introducción de la explicación pragmática, se analiza el tratamiento de este tipo de información en los diccionarios de aprendizaje de español como 
lengua extranjera actualmente publicados. Se analizan los tres diccionarios mencionados, no con el ánimo de compararlos y evaluarlos, sino para detectar su buen estado de salud, con vistas a mejorarlos en propuestas futuras. El destinatario de esta obra, en tanto que consulta el diccionario como herramienta no solo decodificadora sino también codificadora, necesita un sostén firme sobre el uso de las palabras. Para ello, la lexicografía debe continuar el camino iniciado de incorporación de los valores pragmáticos de algunas voces condicionadas por el uso. Dicha andadura puede hacerse con paso más firme, tanto desde el punto de vista del lexicógrafo como desde el del destinatario del diccionario, si se sostiene sobre un patrón uniforme para dar cuenta de tales usos.

\section{LA BÚSQUEDA EN EL DUE DE LA EXPLICACIÓN PRAGMÁTICA EN LAS DEFINICIONES}

Como hemos apuntado, nos acercamos a la versión digital del $D U E$ con el ánimo de buscar constantes en el modo de introducir explicación pragmática. Buscamos en el artículo lexicográfico una serie de expresiones verbales que presuntamente pueden dar cabida a estos valores pragmáticos, tales como indica, manifiesta, se aplica, etc.

Una vez observados los usos de tales verbos en las definiciones, contemplaremos la estructura argumental de los verbos que hayan resultado pertinentes para la introducción de la explicación pragmática. Dicho de otro modo, procederemos a analizar sintácticamente las expresiones verbales empleadas por María Moliner para vehicular la explicación pragmática, de modo que, a partir de tales verbos y de su estructura argumental, pueda esbozarse la propuesta de un patrón de explicación pragmática.

Presentamos a continuación en forma de tabla (1) los expresiones verbales que, a priori, hemos considerado como posibles introductorias de esta explicación pragmática. Señalamos el número de ocurrencias y los posibles usos.

\begin{tabular}{|l|r|l|}
\hline $\begin{array}{l}\text { Expresiones } \\
\text { verbales }\end{array}$ & Ocurrencias & Usos \\
\hline Se usa & 1241 & Información gramatical/explicación pragmática \\
\hline Informa & 10 & Glosa del significado \\
\hline Anuncia & 48 & Glosa del significado/explicación pragmática \\
\hline Señala & - & - \\
\hline Indica & 159 & Glosa del significado/explicación pragmática \\
\hline Se remacha & - & - \\
\hline Manifiesta & 102 & Glosa del significado \\
\hline Se aplica & 1128 & Glosa del significado/ explicación pragmática \\
\hline Expresa & 2209 & Glosa del significado/información gramatical/ \\
\hline Se emplea & 261 & Glosa del significado/explicación pragmática \\
\hline Se utiliza & & \\
\hline & &
\end{tabular}

Tabla 1. Expresiones verbales del DUE

Vemos así que algunas de las expresiones verbales buscadas no sirven para explicar el uso de la voz, como ocurre con manifiesta o informa, que solo aparecen glosando el significado. En general, observamos que no hay expresiones verbales exclusivas para la introducción 
de lo que hemos dado en llamar explicación pragmática. Así, por ejemplo, tales expresiones aportan, en algunos casos, diferente tipo de información secundaria, tal y como ocurre con se usa (1 241 ocurrencias), se emplea (2 209 ocurrencias) o se aplica (8 512 ocurrencias), que introducen también información gramatical, o, incluso, pueden glosar el significado. Valga a continuación un ejemplo de se usa para dar información gramatical:

(1) abstener: Como transitivo no se usa con sujeto de persona. [Información que aparece en notas de uso].

En otros casos, tales expresiones sí que introducen también la explicación propiamente pragmática, como ocurre en las siguientes acepciones de los lemas siguientes:

(2) amigo, -a: $5 \mathrm{n}$. Se usa como apelativo para dirigirse o llamar la atención de un interlocutor, aunque no haya amistad entre ellos: ‘Cuánto le debo, amigo?'.

(3) desgraciado, -a 8 (inf.) Se aplica despectivamente a una persona, para significar que tiene o se le da muy poco valor: ‘¿Qué se ha creído ese desgraciado?’. $\Rightarrow$ *Insignificante.

(4) dominguero, - $\mathbf{a} 2$ adj. y n. Se aplica a la persona que acostumbra a salir y divertirse sólo los domingos o festivos, especialmente a la que sale al campo. $\odot$ En particular, se aplica al conductor torpe que sólo utiliza el coche los domingos o festivos para salir de la ciudad.

(5) visión (del lat. «VISIO, - ŌNIS») 2 *Aparecido, *aparición, *ilusión o *imaginación; cosa que se ve como si fuera real sin serlo. $\odot$ (gralm. pl.) Se emplea en lenguaje informal para decir a alguien que se *equivoca en cierta cosa que cree o afirma. Sólo frecuente en la expresión VER VISIONES. $\Rightarrow$ Alma en pena, alucinación, ánima, *aparecido, *aparición, delirio, entelequia, espanto, espectro, espejismo, espíritu, estantigua, fantasía, fantasma, fantasmagoría, ficción, hircocervo, *ilusión, *imaginación, invención, quimera, sombra, sueño. $>$ *Ilusión.

(6) suponer (del lat. «SUPPONĚRE») 1 Se emplea mucho para ponderar algo que se dice a continuación: 'Ya supondrás, no puedes suponer, ya puedes suponer...' $\simeq$ Que es de suponer.

Algo parecido sucede con las expresiones verbales anuncia (48 ocurrencias), indica (159 ocurrencias), se utiliza (261 ocurrencias) y expresa (1 128 ocurrencias). Algunas veces forman parte de la glosa del significado; otras, introducen la explicación pragmática requerida, aunque, a diferencia de lo que encontrábamos con usa, se emplea o se aplica, las entradas que requieren esa explicación pragmática caen dentro de la fraseología:

(7) Está [o estás, etc.] bueno si... Expresión con que se anuncia que alguien va a tener un chasco o desengaño en cierta pretensión o esperanza: 'Está bueno si cree que le van a dar ese dinero'. $\Rightarrow$ *Chasco, *equivocado, *iluso.

(8) Sin comentarios. Expresión con que alguien indica que no desea hacer declaraciones sobre algo o que no merece la pena comentar algo.

Ante esta primera incursión en las expresiones verbales empleadas para la incorporación de la explicación pragmática, se constata una falta de sistematicidad en su empleo en cuanto al tipo de explicación que pueden introducir. Dicho de otro modo, suelen ser expresiones polivalentes en cuanto al tipo de información que introducen: desde formar parte de la glosa del significado, pasando por la incorporación de información gramatical o incluso de explicación pragmática. Una mayor regularización en los valores conceptuales adscritos a estas ex- 
presiones ayudaría, sin duda, a una mayor coherencia interna del diccionario y a una consulta más eficaz para el destinatario.

Asimismo, llama la atención que algunas de las entradas en que aparece dicha explicación pragmática tienen un rasgo pragmático común. Siguiendo a Qian (1995, apud. Yang 2007), observamos que muchas de las entradas (jefe, caballero, amigo...) en que María Moliner introduce explicación pragmática pueden ser definidas como palabras que refieren información sociopragmática, relacionada con una actitud e intención del hablante y que marca una relación con su interlocutor. Son entradas que, desde el punto de vista pragmático, son definidas como formas de dirigirse o voces para referir relaciones interpersonales (Levinson 1989). Por tanto, de cara a la configuración de la macroestructura de un diccionario de aprendizaje de nueva planta, convendría plantear conjuntamente las explicaciones pragmáticas de estas voces condicionadas por el uso en tanto que formas apelativas de dirigirse a un interlocutor.

\section{PROPUESTA DE UN PATRÓN PARA LA INCORPORACIÓN DE LA EXPLICACIÓN PRAGMÁTICA}

Acercándonos de nuevo a la tabla (1) desde otra óptica, observamos que hay tres expresiones verbales que presentan ocurrencias más altas. Son se usa (1 241), se emplea (2 209) y se aplica (8 512). ${ }^{1}$ Tienen las construcciones con estas expresiones otras coincidencias que interesa resaltar. El análisis de la estructura sintáctica y del valor semántico de estas expresiones permite constatar que, a través de ellas, resulta más ágil la introducción de la explicación pragmática. Por tanto, debido a la alta frecuencia de estas expresiones verbales, parece pertinente centrarse en ellas para extraer un posible patrón de incorporación de la explicación pragmática en los diccionarios con objetivos codificadores.

Nos fijamos para ello, en primer lugar, en los complementos expresos en la estructura sintáctica de la oración con se emplea (ya sean argumentales o adjuntos, ya del verbo principal, ya de una subordinada). ${ }^{2}$ Cabe precisar que en todos los casos se entiende que el lema funciona semánticamente como tema o paciente en la estructura argumental de tales verbos. Veámoslo en el siguiente artículo lexicográfico, que ha resultado especialmente significativo para nuestros fines: ${ }^{3}$

(9) caballero, -a (del lat. «CABALlARIUS») 7 (n. calif.) Se aplica a un hombre que se comporta a

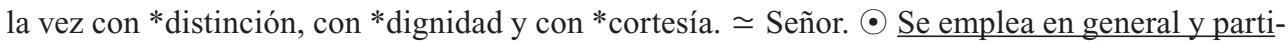
cularmente por las personas modestas, para dirigirse o referirse a lo que suele llamarse un «señor», o sea un *hombre que, por su aspecto o traje, demuestra pertenecer a una clase que no es de obreros; particularmente, como tratamiento de cortesía al cliente de ciertos comercios y otros establecimientos en que se le presta un servicio: 'Caballero: ¿me hace el favor de decirme qué hora es? Atienda a este caballero'. $\odot$ Se emplea para designar los artículos propios de hombre: 'Zapatos de caballero. Sección de caballero'.

${ }^{1}$ expresa tiene también una ocurrencia alta $(1128)$. Sin embargo, como se ha indicado en el epígrafe anterior, el uso de esta expresión para la introducción de la explicación pragmática queda relegada a voces propias de la fraseología.

${ }^{2}$ La expresión verbal se emplea tiene una frecuencia de uso inferior a se aplica. Sin embargo, llama la atención que el uso de esta forma para introducir explicación pragmática sea más habitual en el diccionario que analizamos. Es esta una afirmación que no se sustenta en datos cuantitativos, sino en las apreciaciones de nuestra lectura.

${ }^{3}$ El subrayado es nuestro. 
Los complementos expresos en la estructura sintáctica de la oración con se emplea suponen la activación de los siguientes papeles temáticos, al margen del lema en su forma masculina (caballero) como tema: por un lado, activa el agente de la acción, esto es, quién emplea la entrada $\mathrm{X} ;{ }^{4}$ por otro lado, activa la finalidad de dicha acción, de la que se deriva subordinadamente la meta. Es decir, dichos papeles temáticos, ligados a la estructura argumental de se emplea, esquematizan la situación de enunciación de la voz caballero como apelativo. El verbo en pasiva se emplea conlleva un argumento que semánticamente es el agente y pragmáticamente supone el emisor (por parte de las personas modestas). A su vez, la finalidad puede dar cabida a la introducción del destinatario del enunciado desde el punto de vista pragmático ( $p a-$ ra dirigirse o referirse a lo que suele llamarse un «señor»). Por otra parte, tal construcción permite también la introducción de adjuntos — como vemos en el ejemplo citado_ muy válidos desde el punto de vista pragmático: por un lado, da pie a introducción de información contextual (en general y particularmente), o al tenor interpersonal (como tratamiento de cortesía).

En otros ejemplos, vemos como se incorpora la fuerza ilocutiva de la voz. Valgan las siguientes entradas como ilustración:

(10) señor, -a (del lat. «SENIOR, - ŌRIS») $1 \mathrm{n}$. Persona que no pertenece a las clases populares, esto es, que no se gana la vida trabajando corporalmente y lo denota así en su traje y aspecto. $\underline{\mathrm{Se}}$ emplea esta designación cuando se quiere establecer la diferencia: 'Se puso el traje nuevo y parecía un señor'.

(11) agradar (de « $\left.\mathrm{a}^{2}{ }^{2}\right\rangle \mathrm{y}$ «grado ${ }^{1} »$, gusto) intr. Causar en el ánimo o los sentidos una impresión tal que el sujeto se siente bien con ella y desea que continúe. $\simeq{ }^{*}$ Gustar. $\odot$ En el uso corriente se emplea cuando esa impresión es moderada o producida por cosas de no mucha importancia: 'Me agrada oír un rato música ligera. Me agrada ver a la gente alegre'. No se diría, en general, 'me agrada la Sexta Sinfonía' o 'me agradaría ver felices a mis hijos'.

(12) otra vez. 1 Sirve para expresar la *repetición de una cosa: 'Otra vez se me ha parado el reloj'. $\simeq$ De nuevo. $\odot \underline{\text { Se emplea mucho para expresar un propósito, una indicación o una orden para }}$ el *futuro, basados en algo ya ocurrido: 'Otra vez lávate las manos antes de coger el libro. Otra vez no me cogerán desprevenido’. $\Rightarrow$ Condecabo. $\Rightarrow$ Volver a. 2 A veces, en lenguaje conversacional, expresa devolución, o realización de la acción inversa de otra realizada antes: 'Devolver es dar otra vez lo que se ha recibido prestado. He colocado otra vez el jarrón en su sitio'. $\Rightarrow$ *Volver. (13) telefonazo («Dar; Sonar») m. Llamada telefónica; se emplea con cierto énfasis, indicando, por ejemplo, que causa sorpresa o que se trata de una llamada rápida, solamente para dar un aviso o noticia: 'Si me necesitas, no tienes más que darme un telefonazo'.

Por lo que puede contemplarse en los ejemplos previos, el modo de expresar esa fuerza ilocutiva se refleja sintácticamente en una gran variedad de construcciones sintácticas que dan cauce a un adjunto que activa el papel temático de finalidad: bien bajo construcciones finales (para expresar un propósito; para dar un aviso o noticia), bien a partir de una construcción temporal (cuando se quiere establecer la diferencia), etc.

Asimismo, siguiendo con los posibles adjuntos adscritos al verbo se emplea, tropezamos con lo que desde el punto de vista semántico sería el locativo y el instrumento. Dichas funciones semánticas se traducen en diversas funciones pragmáticas, como puede ser el regis-

${ }^{4}$ Llama la atención la explicitación del agente en esta construcción de pasiva refleja, en la que desde el punto de vista normativo el se bloquea la aparición del agente. 
tro (en lenguaje informal), la modalidad oracional (con tono exclamativo, en frases de sentido negativo), la modalización (en forma reiterativa, llamada rápida, hiperbólicamente, con sentido afectuoso):

(14) a ver 3 Se emplea en lenguaje coloquial para *llamar la atención de una persona antes de decirle u ordenarle algo: '¡A ver...! Que den un paso adelante los de la primera fila'. $\simeq$ Vamos a ver. 4 (inf.) También con tono exclamativo equivale a «iclaro!» y se emplea particularmente cuando alguien confirma por fin una cosa que se negaba a reconocer: 'Pues creo que tenías razón. - ¡A ver...!'. 5 ¡A ver qué vida!

(15) revolver (del lat. «REVOLVĔRE») 11 tr. Hacer girar una \parte del cuerpo o el $\searrow$ cuerpo mismo: 'Revolver los ojos [o la cabeza]'. $\odot$ prnl. Volverse girando. $\odot \underline{\text { Se emplea en frases de }}$ sentido negativo para ponderar la pequeñez del espacio de que se dispone: 'Si ponen en el cuarto una cama, ya no pueden revolverse'.

(16) reviejo, -a 1 adj. Muy *viejo. Se emplea en general en forma reiterativa, pospuesto a «viejo», y aplicado a personas: 'Un viejo, reviejo'.

(17) vacío, -a (del lat. «VACĨVUS») $\mathbf{1}$ («de») adj. Se aplica al recipiente o espacio que contiene solo aire o no contiene la cosa de que se trata: 'Una botella vacía. Una habitación vacía' (sin muebles). $\odot$ Sin gente o sin habitantes: 'La calle estaba a esa hora vacía. La casa tiene todas las persianas echadas, como si estuviese vacía'. $\odot$ Se emplea hiperbólicamente con el significado de «poco lleno»: 'El teatro estaba vacío'.

(18) tuno, -a 1 adj. y n. Tunante. Corrientemente, sólo se emplea con sentido afectuoso: 'El muy tuno sabe decirme lo que más me gusta'.

(19) telefonazo («Dar; Sonar») m. Llamada telefónica; se emplea con cierto énfasis, indicando, por ejemplo, que causa sorpresa o que se trata de una llamada rápida, solamente para dar un aviso o noticia: 'Si me necesitas, no tienes más que darme un telefonazo'.

Sirva también este último ejemplo (19) como constancia de que en ocasiones puede aparecer recogido, si es pertinente para el uso, el efecto perlocutivo de la voz (que causa sorpresa).

Algo parecido a lo que hasta el momento hemos comentado con la expresión verbal se emplea ocurre con se usa, que da cabida a una variada explicación pragmática, como la modalidad (apelativo), el destinatario (para dirigirse a un hombre que tiene cierta autoridad por el trabajo que realiza o por otra circunstancia), la fuerza ilocutiva (para llamar la atención):

(20) amigo: $5 \mathrm{n}$. Se usa como apelativo para dirigirse o llamar la atención de un interlocutor, aunque no haya amistad entre ellos: ‘¿Cuánto le debo, amigo?'.

(21) jefe, -a (del fr. «chef») 2 (pop. e inf.) m. Se usa como apelativo para dirigirse a un hombre que tiene cierta autoridad por el trabajo que realiza o por otra circunstancia; por ejemplo para dirigirse a un conductor de autobús o a un camarero.

Cabe llamar la atención en estos ejemplos sobre un aspecto pragmático apenas reflejado en los casos anteriores: se explicita la relación entre los interlocutores (aunque no haya amistad entre ellos; cierta autoridad), lo que desde el punto de vista pragmático se entendería como el tenor interpersonal.

Por último, la expresión verbal con se aplica permite también la introducción de otro argumento, fundamentalmente con una función semántica de meta, y que proyecta lo que pragmáticamente será el referente. 
(22) desgraciado, -a 8 (inf.) Se aplica despectivamente a una persona, para significar que tiene o se le da muy poco valor: ‘¿Qué se ha creído ese desgraciado?’. $\Rightarrow *$ Insignificante.

(23) pasada: 10 (inf.; n. calif.) Se aplica en tono admirativo a una cosa *extraordinaria: 'Las hoces de este río son una pasada. Tiene un chalé que es una pasada'.

(24) dominguero, -a 2 adj. y $\mathrm{n}$. Se aplica a la persona que acostumbra a salir y divertirse sólo los domingos o festivos, especialmente a la que sale al campo. $\odot$ En particular, se aplica al conductor torpe que sólo utiliza el coche los domingos o festivos para salir de la ciudad.

En cualquier caso, superado el umbral de la funciones sintácticas y semánticas asociadas a las expresiones verbales analizadas (se emplea, se usa, se aplica), lo cierto es que estas permiten, por los complementos expresos que reciben en la estructura sintáctica de la oración (ya sea argumentales o adjuntos, ya del verbo principal, ya de una subordinada), la incorporación de gran cantidad de explicación pragmática, algo que en absoluto pasó desapercibido a la lucidez lexicográfica del así bien llamado Diccionario de uso del español, de María Moliner.

A partir de este sucinto bosquejo, podemos empezar a elaborar un patrón para la explicación pragmática que dé cabida a la información pertinente para el uso adecuado y eficaz de la voz. Los datos pragmáticos recogidos para ser tenidos en cuenta en la explicación de las voces que los requieran son: emisor, destinatario, referente, información contextual, tenor interpersonal, registro, modalidad, modalización, fuerza ilocutiva y efecto perlocutivo.

\section{INCORPORACIÓN DE LA EXPLICACIÓN PRAGMÁTICA EN LOS DICCIONARIOS DE APRENDIZAJE}

Una vez hecha esta primera exploración en la lectura digital del DUE y esbozado así ese patrón de explicación pragmática, tomamos algunas de las entradas sustantivas, adjetivas y verbales que han resultado significativas en la búsqueda del $D U E$, y vemos cómo resuelven esos valores de uso los diccionarios de aprendizaje seleccionados.

Cabe señalar que el diccionario Salamanca incorpora como novedad unas marcas específicamente denominadas pragmáticas, ${ }^{5}$ si bien tanto en el DIPELE como en el DEE también es frecuente el uso de marcas, aunque no llamadas así explícitamente:

(25) jefe, fa $s . m / f: 3$. Coloquial. Tratamiento que se da a una persona conocida con la que se tiene confianza o que tiene cierta responsabilidad: ¡Eh, jefe, pásame un pitillo!, ¡Jefe! ¿tiene una mesa? (Salamanca).

pasada $s . f .4$ (no contable) COLOQUIAL. Cosa o acción que sorprende porque es exagerada en algo. Rafa se ha comprado una moto que es una pasada. Me parece una pasada que nos hayan invitado a todos a comer (Salamanca).

pa.sa.da -5 fam. Cosa que destaca por estar fuera de lo normal: ¡el concierto de ayer fue una $\sim$, fíjate en esa esmeralda, es una $\sim(D I P E L E)$.

pa.sa.do, da adj. $11 \mathrm{col}$. Lo que destaca por su exageración, por su calidad o por salirse de lo normal: Este palacio es una pasada (DEE).

telefonazo s.m. COLOQUIAL. Llamada telefónica breve: Dame un telefonazo antes de salir y te esperaré en la calle (Salamanca).

\footnotetext{
${ }^{5}$ Amenaza, ánimo, despedida, humorístico, intensificador, negación, presentación, sorpresa, afectivo, anticipador narrativo, disgusto y enfado, infantil, ironía, petición, resumidor final, tratamiento, afirmación, contestación a presentación, insulto, peyorativo, saludo.
} 
te.le.fo.na.zo m. fam. Llamada por teléfono:cuando llegues a casa me das un (DIPELE). te.le.fo.na.zo s.m. col. Llamada telefónica: Cuando vaya a salir, te daré un telefonazo. $\square$ Se usa más con los verbos dar o pegar. (DEE).

En ocasiones, se usan otras fórmulas más convencionalmente lexicográficas, expresas en las notas de uso: se usa como apelativo; se usa como insulto.

des.gra.cia.do, da, $-\boldsymbol{m} . f$. Persona que merece desprecio: ese $\sim$ nos ha vuelto a jugar una mala pasada. $\square$ Se usa como apelativo despectivo (DIPELE).

des.gra.cia.do, da adj./s.2. desp. Que inspira menosprecio: Ese desgraciado ha vuelto a aprovecharse de mí. $\square$ Se usa como insulto $(D E E){ }^{6}$

do.min.gue.ro, ra -2 Persona qu suele salir a divertirse y distraerse sólo los domingos y festivos: El campo estaba lleno de domingueros. $\square$ Tiene un matiz despectivo. (DEE).

O bien de forma codificada en la definición: Forma de tratamiento. Tratamiento.

je.fe, fa $\boldsymbol{m} . f .3 \mathrm{fam}$. Forma de tratamiento que indica afecto y respeto: $; \sim !$, olvida usted el paraguas (DIPELE).

je.fe, fa $4 \mathrm{col}$. Tratamiento que se da a una persona que tiene algún tipo de autoridad: Jefe, póngame cuando pueda una cañita y unas aceitunas (DEE).

caballero, ra s.m. 6. RESTRINGIDO. Forma de tratamiento de cortesía que equivale a señor: Es normal que en muchas tiendas y bares un empleado nos diga: “¿Qué desea, caballero?” (Salamanca).

ca.ba.Ile.ro m. 4. Forma de tratamiento que indica respeto y * cortesía y que se *utilizar hacia los hombres: joiga!, , olvida usted su paraguas (DIPELE).

ca.ba.lle.ro s.m. 2 Hombre adulto: ¿Dónde está el servicio de caballeros, por favor? ฉ Se usa como tratamiento de cortesía $(D E E)$.

En otras ocasiones, no se recoge el valor de uso señalado por el $D U E$ a dicha voz; puede considerarse que son voces o acepciones en desuso, tal como sucede con revolver o reviejo, pero no siempre es esta la razón. Tal ocurre con agradar y otra vez, entradas en las que ninguno de los tres diccionarios consultados explican en su artículo lexicográfico las condiciones de uso. Otras voces corren mejor suerte y son recogidas en alguno de los diccionarios consultados. Es el caso de amigo (recogida en $D E E$ ) o de suponer y tuno (recogidas en Salamanca).

En general, se echa de menos la incursión de la explicación pragmática en la definición. Szczepaniak (2006: 133) y Yang (2007: 170) señalan el hecho de que la explicación pragmática, más allá de las notas y marcas, se recoge en la definición lexicográfica de los diccionarios de aprendizaje de un modo irregular. Llama la atención que los tres diccionarios consultados evitan mayoritariamente la explicación pragmática dentro de la definición, incluso omitiendo tal uso como acepción. De todos modos, valga como excepción la incursión de definiciones impropias que dan cuenta de la explicación pragmática en algunas de las voces consultadas en el $D E E$, aunque no se proceda de manera sistemática en la incorporación de dicha explicación. Como ejemplo se recoge:

\footnotetext{
${ }^{6}$ En el diccionario Salamanca no se recoge tal valor en la voz desgraciado, da.
} 
(31) se.ñor, ño. ra adj. 1 co. Seguido de algunos sustantivos, intensifica o da fuerza al significado de estos: Vive en una señora casa. Tienes un señor problema y no puedo ayudarte (DEE).

ver $\|$ a , col. Expresión que se usa para pedir algo o para indicar interés o curiosidad: $A$ ver, ¿qué es lo que no entiendes? (DEE).

Un diccionario de aprendizaje necesita, en virtud de su destinatario, dar un peso muy alto a la pragmática codificada en el léxico. Las muestras presentadas demuestran que tales diccionarios publicados en español gozan, en este sentido, de buena salud, pues incorporan, a través de marcas o notas de uso, información referente al registro, a la modalidad, a la fuerza ilocutiva. Sin embargo, no parece que se proceda de una forma sistemática en la incorporación de dicha explicación en el cuerpo de la definición. Sería conveniente, sin embargo, a la luz del análisis del $D U E$, la inclusión de varios elementos en la explicación pragmática que asegure el uso eficaz de estas voces por usuarios no nativos que, por lo tanto, tienen unos marcos conceptuales más limitados para poder presuponer o implicar la explicación pragmática que a un nativo le puede resultar más fácil.

Como señala Jiménez, «si, efectivamente, el diccionario /gramática ha de ser tipológica, psicológica y socialmente válido, así como textualmente adecuado para los fines comunicativos del emisor y receptor, el componente pragmático será por su propia naturaleza el componente más importante» (2001: 87). Para ello, ha de conseguirse una explicación pragmática sistematizada del léxico. Esto significa, siguiendo a esta autora, integrar los rasgos pragmáticos o las condiciones de uso en las representaciones de las entradas léxicas. La característica básica de la concepción de la pragmática codificada en el léxico es, pues, contribuir a la creación de una tipología del discurso donde se describa todas los tipos de situaciones posibles en las que participe el hablante, atendiendo para ello a aquellas informaciones que señalan las condiciones de comunicación de la unidad léxica. En este sentido, como subraya Jiménez, «el lexema ha de considerarse un factor que influye o modifica el contexto discursivo para el que es seleccionado por un interlocutor que, en ese momento, está estableciendo una serie de preferencias no solamente lingüísticas sino psicológicas, estilísticas, sociológicas, discursivas, etc.» (2001: 89). Y no solo preferencias, sino análisis de los requisitos de la situación comunicativa.

\section{CONCLUSIONES}

La exploración efectuada en la versión digital del $D U E$ ha permitido extraer una lista de posibles expresiones verbales cuya estructura sintáctica, por su estructura argumental y los papeles temáticos que activan, parece hacer más ágil la introducción de la explicación pragmática. El análisis de tales expresiones y su estructura sintáctica ha permitido un primer patrón para sistematizar la explicación pragmática de las voces que lo requieran en la microestructura del artículo lexicográfico.

El estado de la cuestión en los diccionarios de aprendizaje existentes revela lo esperable. La explicación pragmática aparece explícitamente señalada bien sea a través de las marcas pragmáticas del Salamanca, bien a través de las notas de uso del DIPELE y del DEE. Sin embargo, la información codificada de este modo resulta insuficiente para un uso eficaz de tales palabras en una situación de enunciación. Tan solo el $D E E$ introduce en ocasiones explicación pragmática sobre el uso de las voces. 
Para que el diccionario resulte eficaz como herramienta de codificación parece necesario que dicha explicación se recoja de forma sistematizada, para facilitar la lectura y la coherencia interna del diccionario. El análisis efectuado ha permitido plantear explicaciones pragmáticas de las voces agrupándolas según condiciones de dichas voces. En este sentido, vale la pena señalar que hemos constatado la necesidad de explicación pragmática en voces apelativas. Asimismo, una fórmula estudiada de explicación pragmática que recogiera los argumentos y los adjuntos que expresiones verbales como se emplea, se usa, se aplica requieren o permiten, repercutiría en la precisión de esta información, y por lo tanto, en la decodificación y codificación de la misma por parte del usuario, entendiendo de este modo la Pragmática como un estímulo para representar en la mente del otro la realidad.

\section{REFERENCIAS BIBLIOGRÁFICAS}

Albert GalerA, Josefina (1996): «La pragmática en los diccionarios españoles», en E. Forgas, coord., Léxico y Diccionarios, Tarragona, Universidad Rovira i Virgili, pp. 7-23.

BAtTANer, Ma Paz (2005): «Dos casos de definiciones morfológicas en los diccionarios», en L. Santos Río, J. Borrego Nieto, J. F. García Santos, J.J. Gómez Asencio y E. Prieto de los Mozos, eds., Palabras, norma, discurso. En memoria de Fernando Lázaro Carreter, Salamanca, Universidad de Salamanca, pp. 125-135.

Bosco, Francesca M., Monica Bucciarelli y Bruno G. BArA (2006): «Recognition and repair of communicative failures: A developmental perspective», Journal of Pragmatics, 38, 9, pp. 1398-1429.

Chan, Alice Yin Wa y Andrew TAYlor (2001): «Evaluating Learner Dictionaries: What the Reviews Say», International Journal of Lexicography, 14, 3, pp. 163-180.

Casado Velarde, Manuel (1994): «La información textual en el DUE de María Moliner», en Voz y Letra, 5, 1, pp. 129-137.

CoRpas, Gloria (1998): «Criterios generales de clasificación del universo fraseológico de las lenguas, con ejemplos en español y en inglés», en M. Alvar y G. Corpas, coords., Diccionarios, frases, palabras, Málaga, Universidad de Málaga, pp. 157-187.

JiMÉNEZ, Catalina (2001): Léxico y Pragmática, Frankfurt, Peter Lang.

LEECH, Geoffrey (1983): Principles of Pragmatics, London, Longman.

LeEch, Geoffrey y Jenny Thomas (1987): «Pragmatics and the Dictionary», en Longman Dictionary of Contemporary English, London, Longman, pp.13-14.

Levinson, Stephen C. (1989): Pragmatics, Cambridge, Cambridge University Press.

Martín Mingorance, Leocadio (1990): «Functional Grammar and Lexematics in Lexicography», en J. Tomaszcyk, y B. Lewandowska-Tomaszcyk, eds., Meaning and Lexicography, Amsterdam, John Benjamins, pp. 227-253.

NUCCORINI, Stefania (1993): «Pragmatics in learners' diccionaries», Journal of Pragmatics, 19, 3, pp. 215-237

RUIZ GuRILlo, Leonor (2000): «Cómo integrar la fraseología en los diccionarios monolingües», en Gloria Corpas, ed., Las lenguas de Europa: estudios de fraseología, fraseografía y traducción, Granada, Comares, pp. 261-274. 
Sinclair, John, ed., (1987): Looking up, London y Glasgow, Collins.

SzCZEPANIAK, Renata (2006): The Role of Dictionary Use in the Comprehension of Idiom Variants, Tübingen, Max Niemeyer.

Tono, Yukio (2001): Research on Dictionary Use in the Context of Foreign Language Learning. Focus on Reading Comprensión, Tübingen, Max Niemeyer.

Thomas, Jenny (1983): «Cross-cultural Pragmatic Failure», Applied Linguistics, 4, 2, pp. 91-112.

VÁzQUez, Nancy et al. (2002): «Unidades léxicas no descriptivas: un puente entre la lexicografía y la pragmática», en J. I. Pérez Pascual y M. Campos Souto, eds., Cuestiones de lexicografía, Lugo, TrisTram, pp. 235-247.

YANG, Wen Xiu (2007): «On pragmatic information in learners' dictionaries, with particular reference to LDOCE4», International Journal of Lexicography, 20, 2, pp. 147-173.

Wingate, Ursula (2002): The Effectiveness of Different Learner Dictionaries, Tübingen, Max Niemeyer.

ZGUSTA, Ladislav (1988): «Pragmatics, lexicography and dictionaries of English», World Englishes, 7, 3, pp. 243-253.

\section{DICCIONARIOS}

Alvar, Manuel (2000): Diccionario para la enseñanza de la lengua española, Madrid, Vox-Universidad de Alcalá [DIPELE].

Briz, Antonio, coord., Diccionario de particulas discursivas del español, en http://textodigital.com/P/DDPD/.

Gutiérrez Cuadrado, Juan y José Antonio Pascual (1996): Diccionario Salamanca, Madrid, Santillana-Universidad de Salamanca [Salamanca].

Maldonado, Concepción, dir. (2002): Diccionario de español para extranjeros, Madrid, SM [DEE].

Moliner, María (2001): Diccionario de uso del español, Madrid, Gredos, $2^{\mathrm{a}}$ ed. (CD-ROM) [DUE].

SAntos, Luis (2003): Diccionario de partículas, Salamanca, Luso-Española de ediciones.

Seco, Manuel, Olivia Andrés y Gabino Ramos (1999): Diccionario del español actual, Madrid, Aguilar $[D E A]$. 